\title{
Cyber blame and social theory
}

\author{
Barbara Hanson $^{1}$ (D)
}

Received: 28 October 2020 / Accepted: 20 April 2021 / Published online: 6 May 2021

(c) The Author(s), under exclusive licence to Springer Nature Switzerland AG 2021

\begin{abstract}
Cybernetic causality reveals social processes of blaming. It allows for fluid multidirectional causal webs. Looking at blame through a cybernetic lens reveals social construction processes of creation, modification, exacerbation, dissipation, and elimination. Sometimes all at the same time. Performances of blaming can attribute praise or condemnation both simultaneously and sequentially. Blaming is enacted in multiple forms including being a conduit, reducing uncertainty, separation from self, a desire for efficacy, or a search for esteem. Mapping out fluid complexity in blaming might encourage using cybernetic causality to understand more aspects of social experience.
\end{abstract}

Keywords Blaming $\cdot$ Cybernetics $\cdot$ Holism $\cdot$ Performance

Blaming can be usefully modeled as a cybernetic social process. Cybernetic causal dynamics can describe fluid process with multiple liquid, solid, animate, and inanimate parts. Causality can be omnidirectional, infinite, perpetual, and, therefore, everywhere. As analysts we can reduce or punctuate such process as a convenience or necessity. But its worth remembering that as experienced its infinite, fluid, and constantly moving like interconnected bodies of water. This suggests a holistic view that embraces fluid, moving, multi-focal, self-steering compendia of parts, relations, and processes.

In this view we can see a social performance of blaming as a dynamic that is fluid and continuous. Blame is constantly created, modified, and dissipated in processes that steer in different directions at different or the same times and look different from different reference points. Wrong becomes right, right becomes wrong, good becomes wrong, and wrong becomes esteem. Sometimes all at the same time. This complexity and ability to transform can be usefully represented as cybernetic- - selfsteering multiplex causal infusions in fluid social experiences that are constantly moving.

Barbara Hanson

hansonbg@yorku.ca

1 York University, 220 McLaughlin College, 4700 Keele Street, Toronto, ON M3J 1P3, Canada 
This does not deny or negate that there are mechanistic machine-like components to social behavior. Rather it adds fluid non-summative wholes to such components. Thinking of liquid when we try to understand social behavior might help us understand more or at least map some of the dimensions in our gaps of understanding.

\section{Literature review}

This is a theoretical piece that draws on thinking in various literatures and practices including theorizing blame, cybernetics, social performance theory, and a concept of legal person. They lead me to the question - can cybernetic modeling of blaming improve social theory?

Literature on blame is vast. A recent search of scholarly work gave me over 1 million sources with blame anywhere and over 27,000 with blame in the title. I draw on several themes within this. Tilley's work on how the attribution of credit and blame is done, what it means to court cases, and how it shapes political reconciliations shows up how blaming is a significant process (2008). The existence of simultaneous opposed blame/praise is supported by Coates and Tagnazzini (2013). Work from Psychology suggest blame as a social act that is managed in different ways including attributing causality (Malle et al. 2014). This has been shown to happen through assigning blame to those who are not responsible, even if it doesn't make sense and is not rational (Gurdal et al. 2013). It shows up in how seriously ill patients and their care givers attribute blame for illness (Phelan 2013; Rousseau 2011), how populist rhetoric attributes blame to elites and government (Hameleers et al. 2017), and the way blame is bound up with power (Kirk, 2014). The cybernetic and nuanced character of blaming is suggested by research that detects subtle victim blaming even when people say they are not blaming (Hafer et al. 2019), how blame avoidance can be like a game (Hansson 2018), and how avoidance of blame is enacted (Hinterleitner and Sager 2017).

Cybernetics adds to the blame literature by providing a construct of causality in fluid, moving wholes. These ideas about cyber blame as self-steering, multi-focal, and capable of simultaneous, even co-dependent, attributions of right and wrong that come from a large, long time, and diverse body of works on cybernetics like (Jackson and Sambo 2020; Melo 2020; Wallis 2020; Wallis 2014; Guy 2018; Mavrofides et al. 2011; Hanson 1995) and the groundbreaking work of Maruyana (1963), Bateson (1980) and Watzlawick et al. (1967). It also harmonizes with revisions of mechanistic or binary views (Reiter 2020; Knio 2018; Hanson 2014, 1995; Khoury 2013; Foley 2003; Egler 1970; Maruyana 1963) and arguments for more ecological, fuzzy, or leaky categories (Stalker 2019; Hinterleitner and Sager 2017; McDaniel 2003). These works got me thinking about how to portray the fluidity and self-steering patterns of events that emerge in laying blame.

We can use performance theory as set by our authors like Curran (2018), Butler (1999), and Goffman (1959) to suggest that social life is performed in contexts of created and modified sets of meanings, symbols, locations, and identities. We act in social worlds of meaning that are formed and reformed through everyday 
enactments. This provides a link to models of blame as a conversation (Driver 2016) and how persons perform in ways that improve their value (Gray 2011).

In the performance of blame, it is useful to separate blame and blaming. Blaming is the process of constructing, acting out, modifying, and sending out blame. This allows us to portray how blaming is often about trying to stop, end, or contain. But conclusive or stationary blame is not likely sustainable as experienced and not well represented by mechanistic portrayals of cause and effect. Tilley contributes to models of performance by noting the importance of story making that assigns blame and merit (2008). He also notes that "[e]ven if the basic story structure results from wiring in the human brain, the contents of the stories vary with their cultural settings. ..." (2008, p. 41). Work on blaming fat persons suggests that blame can be seen as a "devastating relation of power" (Kirk et al. 2014). This connects to ideas about the way relations of ruling are enacted in everyday life (Smith 1987).

Finally I use a legal concept of person in the sense of a party to legal action that can be an individual human being up to a massive corporation, nation, or trading block (Garner 1999). It is a useful addition to social theory and the cybernetic study of blaming because it has the flexibility to work on a wide range of levels. We can talk about person as a transgendered woman wrongfully fired from a job or a national government being sued for its failure to prohibit discrimination based on sexual orientation. This is particularly useful in a cybernetic approach to blame because patterns of causality can be seen in groups of unlimited size and/or form of interconnection. It has been observed by looking at how blame dynamics go on in legal processes like court cases and mediation (Hanson 2016; Nadler 2012; Tilley 2008; Felstiner et al. 1980) in the European Union (Heinkelmann-Wild et al. 2020) and among communities dealing with climate change (Williams 2020). This connects to philosophy that allows for both individual and group blaming (Royakkers and Hughes 2020). Legal person also connects my ideas to thinking about intersectionality as initiated by Crenshaw (1989) and under debate in recent legal studies that portray multi-dimensional social identities (Mant 2020; La Barbera and Lopez 2019). A fluid model of blame that works cybernetically in an infinite number of levels might offer ideas about simultaneous multiplicity. These literatures all contribute to a model of cybernetic social performance of blaming on multiple levels.

\section{Cyber blame}

Cybernetic, cyborg, and cyber (including "Cyber Monday" sales) have come into widespread everyday use to refer to technology, the internet, robots, and digitalization of information. In some contexts, it has come to be about automatic control (BBC Magazine 2016). Cybernetics also has a historic meaning illustrated by the process of steering boats. Staying on route requires constant adjusting back and forth. This is the sense of cybernetics I use as grounded in the literature set out in the previous section.

Applied to blame cybernetic causality reveals how movement and fluidity are endemic to social experience. We constantly steer, individually and/or collectively, on various levels- consciously or not. Its possible to argue that there is no such thing 
as stillness, lack of movement in lived experience. This is inherent in acceptance of the principles of physical existence on a rotating orbiting planet among other planets and astronomical bodies. Human bodies are mostly fluid. There is constant movement within, by, and among bodies. Even after death some bodily processes go on. Social performance happens through moving, fluid, infusing, and interconnections. It rebounds like waves that energize water. It is infinite, omni-directional, multiplex, and multi-focal. So it is with the specifics of blaming.

Blame events can have short- and long-term effects that may be good, bad, or bad and good at the same time. Figuring out whether this is a good thing or a bad thing may be difficult and even impossible to pinpoint particularly in the short term. It depends on who is making the assessment, when, and why.

Theorists punctuate and reduce social behavior out of necessity by setting out a topic or scope for a project. We can't look at or analyze everything, even with the help of ever growing access to digital information, sound, and imagery. So its important to be aware of how we punctuate and reduce-choose what to focus on and what to not focus on. Not looking at cybernetic causal interconnections may miss the essential properties of fluidity and movement. In doing so,it limits what we can find. Being aware of self-steering causal webs is a step toward portraying blaming.

\section{Blame and blaming}

Linked blaming events emerge and co-emerge though back and forth, up and down, stop and start, left and right, in and out, entrance and withdrawal, attention and disattention etc. In other words, a given event emerges through multiplex sources and can come from anywhere. This harmonizes with Foucault's ideas about power that comes from "everywhere" (1980, p. 93).

Blaming permeates practices of social experience in a multitude of ways on an infinite number of levels. It has become increasingly noteworthy in international politics through the use of healing and reconciliation to redress injustice (Tilley 2008). It has also been used to propagate racialization like blaming China for the pandemic (Etzioni 2020). This dynamic has been strongly criticized by Canadian Prime Minister Justin Trudeau (2020). Blaming is replete in disputes ranging from a couple of people to massive legal actions with mediation and restitution among corporations or governments.

Blame can be seen like a ball that is tossed, caught, batted back and forth, held, and made to disappear. It can be enacted in micro-politics (Hansson 2018) and social performance. It strikes, injures, relieves pressure, and inspires juggling or balancing. It may be something persons create to give form or focus to diffuse or unclear feelings - give them a reason for why they are in pain or harden their legal attack. Thus, blame becomes part of a process of blaming as does a ball part of a game.

Blaming a person (from a single human to a nation) for something bad that happens can initially be resisted by the person being blamed, then the person accepts responsibility, apologizes, makes amends, and gains integrity because of this. Blame thus goes from a bad thing to a good thing. It can be bad again if the person is seen 
as insincere or tries to profit from the process. It can continue in a multitude of ways and directions in terms of whether being blamed is desirable, undesirable, or even both at the same time.

From a cybernetic view, its even possible to argue that fixing blame in a person violates the principle of non-summativity in the case of families in distress who attempt to lay blame on a single member when the relevant causal connections permeate the whole group (Hanson 1995). Persons create, manage, direct, and modify blame. These can be seen as performances (Joyce and Jeske 2019; Curran 2018; Butler1999; Goffman 1959).

\section{Blame performances}

Persons use blaming to try to navigate, cope, and gain advantage. So its important to look carefully at how and why it gets used. Holism and cybernetics offer a way to frame causal steering sequences that are not necessarily linear, have different effects and meanings in different systems, and can mean multiple things at the same time.. Parties or persons in the legal sense, even if a single human, might feel differently about blaming at different times or have multiple conflicting feelings about blaming at the same point in time. This can be different in different contexts.

Mediators, counselors, lawyers, teachers, parents, negotiators, managers, day care workers, diplomats, gov't officials, heads of state, or therapists who see this might use it to move persons in a desired direction. Accepting blame or responsibility can be very valuable. This has shown up in actions like the Canadian Government accepting responsibility and apologizing for the Residential Schools system that attempted to forcibly assimilate Indigenous persons by taking children away from their families and indoctrinating them into European settler culture (Trudean 2017). This echos the healing and recognition that has gone on in South Africa including Nelson Mandela becoming president (Tilley 2008).

Persons often get relief from being heard about blaming. Sometimes the opportunity to voice what they feel and how they have been hurt allows them to bring closure to an issue. Disputes might be moved toward resolution through this. Some criminal justice systems allow victims of crime and/or their family members to confront the perpetrator and vent blame at them for the pain they have caused. This is a way to help the victims acknowledge their suffering and being wronged by the perpetrator. Sometimes convicted perpetrators are given the chance to accept blame and apologize. Indeed this might be an expected part of asking for a less severe sentence or earlier parole.

Blaming is slippery. It moves. It changes value, form, and polarity-whether it is a good or bad thing. This makes it difficult to pin down. It is all the more interesting for this as persons act out blaming dynamics.

Cyber causality allows us to think about blaming in continuous multiplex causal sequences with punctuation points where the location and participation of blame can be described. It suggests watching for back and forth patterns that steer a system. This means that laying blame on a person or part of a system is just part of a process 
and can reveal motivations among persons entwined in the dynamic. This can provide ideas about how blaming dynamics play out and become entangled.

Persons can get caught up in the current of blaming even though its steering toward negative result like "winning" a court case by having a person blamed at a cost in legal fees that is much greater than amount awarded to the "winner". Persons may risk such disaster in order to have another person blamed.

This suggests blaming acts like a fuel, gasoline poured on a fire that starts a blaze even if the fire is almost out and smoldering. But it can also steer to calm down and even extinguish a conflict. By analogy it might work like a gas-powered refrigeration unit or a fire deliberately set by firefighters to extinguish another fire. Below I set out some interrelated dimensions of blaming performances to give form to this flexibility and mutability.

\section{As a conduit}

Separating blaming from blame conceptually allows seeing that blaming is a process while blame is more like an object that is fought over and played with. It rests in different places. Sometimes stays put. Sometimes relaunches. Sometimes disappears. All these motions and recreations can be part of a process of blaming. Blame is the object or goal while blaming is how humans express and use blame to various ends.

As such, blame can be thought of as a conduit - a place to park or shelve negative emotions like uncertainty, low self-esteem, fear, betrayal, loss, regret, guilt. Once a person is blamed, there may be relief. There is an answer to what is upsetting, scary, or dangerous. For example, a son with a terminally ill mother might ask a doctor "Did I do this?" with some action or inaction (Rousseau 2011). Uncertainty can be uncomfortable to the point that even a painful answer is preferable to a worrisome question.

This may be more acute if the worrier fears that they may be to blame themself. It was the neighbors trash rather than the onion I gave my dog that killed him. Even learning that it was your onion might be easier to take than not knowing what killed your dog.

At the level of nations or markets, this could reflect in the way stock market values tend to drop in reaction to uncertainty and rise in response to clarity like knowing who the country's next leader will be or the resolution of a crisis. This is something investment agents might track and use to their advantage. It shows up in the way uncertainty over the Corona virus crisis contributed to major falls in stock markets and hoarding of grocery products.

\section{Reduction of uncertainty}

[Hum]ankind loves a mystery, but it hates a mystery more. ... (Egler 1970, p. 1)

Some of the appeal of blame lies in its ability to render things explicable. We crave understanding that will reduce the complexity of a situation to a level that is 
manageable. Blaming, thus, meets an immediate emotional need to reduce confusion. It may be motivated to some extent by a need to put things in categories that make sense and allow a level of comfort that lies in having an explanation-even if this is temporary or creates another level of discomfort. For example, suppose someone you trust or love is to blame. Blaming them may be less painful than not having an explanation for what is going on. Or, a person may be blamed even if they are not responsible (Gurdal et al. 2013).

A person facing a law suit can weigh the cost of legal fees and damages against the cost of settling. Settlement might have the added appeal of negotiating an acceptance or avoidance of blame. It is also certain unlike the unpredictability of court findings.

So persons might act to avoid being blamed themselves by blaming other(s). This may give a blamer some relief from confusion and anxiety that comes from not knowing what is going on or wanting something painful to end. Another example is awaiting a decision on whether you are offered a job, pass a course, get tenure, or have an article accepted. While a positive result will make you happier, even a negative result that makes you angry at whoever made the decision will relieve the anxiety of not knowing.

Through a process of blaming we try to assign categories. Who is to blame, me or him/her, us or them/that? Answering this question is a way to order what may be a messy complex situation. With a lung cancer diagnosis this may involve a person accepting that they should have quit smoking (Hanson 2010). At a institutional level this can be seen in assigning blame to various USA money market players for the financial meltdown that ensued from the 2008 Stock market crash. Regrettably this included racialized blaming of persons who loaned money to marginalized groups (Zebellos-Reig 2020).

Persons search to contain and compartmentalize something amorphous. This may fuel steering toward assigning blame. Indeed some authors working within systems epistemology have suggested that “... uncertainty can attract a living system to higher complexity" owing to "... the inability of an observer to establish a causal explanation" (Mavrofides et al. 2011, pp. 360, 361).

So persons may look for blame in a finite causal sequence containable in a person. But such linear causal explanations may disappoint given the tendency for systems to exhibit cybernetic causality and self-steer in unanticipated directions. This lack of fit may fuel more desire to blame particularly if the person pushing for blame feels a need to exempt her/his/their or itself.

\section{Separation from self}

Laying blame on a person other than you may appeal both as a way to reduce uncertainty and self-benefit. Its a way to try to shift the feared event of you getting blamed onto another target. Persons try to avoid the negative consequences of being blamed such as people disliking you, being sent to the corner, status or financial loss, criminal punishment, etc. Even if you don't blame someone else you might work to establish that is was "not me". This can work with laying blaming on "the system" 
(Vanderstraeten 2019). Or, people might use a concept of a past self that is removed from their current self to deal with former wrongdoing (Ernst et al. 2019).

This strategy allows separation of self, the location where you are, from another location. At essence its a mechanistic notion in that it attempts to see a phenomena in component parts. Before attributing blame somewhere else its necessary to be able to place a boundary between self and something or someone else.

Once there is potential for separation its possible to classify troubling things into good/evil, right/wrong, redresssive/regressive, helpful/destructive, noble/dishonorable etc. One author argues that this is at work when governments deflect blame for inadequacy of social assistance by giving discretionary powers to local authorities (Meers 2019). Even when the process stays internal to a single human there is the possibility for separating out one aspect of yourself. This comes out in health issues where a person blames themself for a destructive behavior like substance abuse by admitting they do it. This can be seen as a move from focusing on self-blame to targeting something else as blameworthy.

I have come to think about this as a moving from "me" to "it". Even if the bad, blame target, is within one's physical body there is an emotional separation from a person who now can put blame onto something that they can't control, an external force which they resist. This is a way to establish a positive view of self. A person becomes noble for their attempts to fight against something that is bad while they are good. In so doing blaming this entity may allow a person to move to a healthier behavior pattern. There is a space to establish an identity that is not dominated by the force of substance abuse, or illness.

Separation into discrete parts is a precursor to assignment of blame to a part. Cybernetic causality helps visualize how systems tend to self-steer, often in non-linear ways. So if we try to move blame onto a discrete part it may just come back at us. Apropos of this issue I recall the quotation "Treason doth never prosper. What's the reason? Why, for if it prosper, none dare call it treason". (Harrington 1561-1612). As alliances shift so does the locus of blaming. Blaming shifts in form and location as persons attempt to cut themselves off from being blamed through various causal steering patterns. There are many forms of systems concepts that can helps model this complexity (Wallis 2020, 2014).

\section{Desire for efficacy}

Blaming may also be fueled by a desire for efficacy - the idea that you can do something. I am thinking here about the way persons may go through a process of blaming themselves when something horrible happens, like the death of a loved one. Its not unusual that surviving loved ones will go through a process of blaming themselves for something they did or did not do. If only I'd gotten her to that specialist. I should have forced him into that clinical trial. Why didn't I turn down that promotion so that we could travel more? Its possible to argue that this is a way for self to reach for efficacy in the sense that looking for things done wrong suggests that you could have done things right and prevented the horrible event. 
So even self-blame has the benefit of a sense of control or efficacy, a belief that one's actions or inactions could have made a difference. Even the painful idea that you made, let, or did nothing to stop something bad may be preferable to the idea that you were helpless. This shows up in how persons try to cope. Unthank provides a detailed analysis of the way this plays out in the survival of sexual abuse in terms of being both empowering and dis-empowering (2019). Cyber blame can capture such multidirectional and opposite reactions from the same stimulus. (Hanson 1995).

\section{Search for esteem}

Blaming may be important to think about in terms of its role in a search for esteem in the sense of value or merit. This can happen in a number of ways. Persons can gain esteem through accepting blame, and making amends, with or without apologizing. I sense this process is something that is keyed on in marketing. Persons gain esteem by buying or producing composting bins, hybrid SUVs, energy efficient appliances, and biodegradable laundry soap. These products both attribute blame by pointing to ecologically destructive practices and offer a chance for a person to make amends through some ameliorative effort.

This process has been examined in detail in terms of multi-level systems and blame games in the European Union (Heinkelmann-Wild et al. 2020). Research from psychology highlights how subtle victim blaming is motivated by a desire to see the world as good or just (Hafer et al. 2019). This may include seeking esteem by being seen as a victim (Gray 2011) and the negative impact on fat persons of being held responsible, blamed, for being fat (Thörel et al. 2020). These examples show up how persons may seek self-esteem by isolating and externalizing troubles.

Even where blame is attached, the person blamed can begin to separate the trouble from themself by making restitution, often including an admission of blame and/ or apology. This surfaced in the build up to the US military invasion of Iraq. Early in the process I recall a joke going around. "How does the US know there are weapons of mass destruction in Iraq? .... They still have the receipts". This began as a condemnation of the USA, but later came into the justification for invasion. The USA knew the weapons were there because they sold them to Iraq. Thus, blame for past mistakes got spun into a worthy justification for going and fixing these mistakes.

In this way, infamous acts become something that a person did that was bad rather than evidence that the person is bad, particularly if we admit our mistake and try to fix it. So there is a benefit to the blamed person in terms of self-worthiness or esteem. It also bears elements of rendering a complex and emotionally loaded situation more understandable and giving the opportunity to isolate the bad act(s) from the person through admission and worthy acts. Any or all of the types of performances set out above may be involved in a given blaming sequence. 


\section{Conclusion}

Can cybernetic modeling of blaming improve social theory? I think so, because it adds fluidity and movement to models of linear causality and fixed category boundaries. This allows a fuller portrayal of social experience as performance. We can see things about blame and lived fluidity by looking at ways blaming is performed as conduit, explanation, separation, self efficacy, and/or self esteem. This might be a beginning point to looking for self-steering, multi-focal, and omni-directional connections in practices of doing, creating, and modifying other types of performances of social life.

Acknowledgements I thank the two anonymous reviewers who made helpful comments that guided revision.

Funding No funds, grants, or other support was received.

Data Availability The article is not data based. It is a theoretical think piece.

\section{Declarations}

Conflict of interest On behalf of all authors, the corresponding author states that there is no conflict of interest.

\section{References}

Bateson G (1980) Mind and nature: a necessary unity. Bantam Books, Toronto

BBC Magazine (2016) The vocabularist: how we use the word cyber. https://www.bbc.com/news/magaz ine-35765276

Butler J (1999) Bourdieu: a critical reader. In: Shusterman R (ed) Performativity's social magic. Blackwell, Malden, pp 113-128

Coates DJ, Tognazzini NA (2013) The contours of blame. In: Coates DJ, Tognazzini NA (eds) Blame its nature and norms. Oxford University Press, Oxford. https://doi.org/10.1093/acprof:oso/9780199860 821.003 .0001

Crenshaw K (1989) Demarginalizing the intersection of race and sex: a black feminist critique of antidiscrimination doctrine, feminist theory and antiracist politics. Univ Chic Leg Forum 1989:139-167

Curran D (2018) From performativity to representation as intervention: rethinking the 2008 financial crisis and the recent history of social science. J Theory Soc Behav 48:492-510. https://doi.org/10. $1111 /$ jtsb. 12186

De Melo TA et al (2020) Thinking (in) complexity: (in) definitions and (mis)conceptions. Syst Res Behav Sci 37(1):154-169. https://doi.org/10.1002/sres.2612

Driver J (2016) Private blame. Crim Law Philos 10(2):215-220. https://doi.org/10.1007/ s11572-015-9368-z

Egler FE (1970) The way of science: a philosophy of ecology for the Layman. Hafner Publishing Company, New York

Ernst WM, Spears R, Epstude K (2019) Having pity on our victims to save ourselves: compassion reduces self-critical emotions and self-blame about past harmful behavior among those who highly identify with their past self. PLoS ONE. https://doi.org/10.1371/journal.pone.0223945

Etzioni A (2020) US anti-China sentiment reaches new peak: we're at the wagging the dog stage. The Diplomat. https://www.thediplomat.com/08/2020. Accessed 11 Aug 2020 
Felstiner WLF, Abel RL, Sarat A (1980) The emergence and transformation of disputes: naming, blaming, claiming. Law Soc Rev 15(3):631

Foley D (2003) Indigenous epistemology and indigenous standpoint theory. Soc Altern 22(1):44-52

Foucault M (1980) The history of sexuality: vol. 1: an introduction. Vintage Books, New York

Garner BA (ed) (1999) Black’s legal dictionary. West Group, St. Paul

Goffman E (1959) The presentation of self in everyday life. Anchor Doubleday, Garden City

Gray W (2011) To escape blame, don't be a hero-be a victim. J Exp Soc Psychol 47(2):516-519

Gurdal M, Miller J, Rustichini A (2013) Why blame? J Polit Econ 121(6):1205-1247. https://doi.org/10. $1086 / 674409$

Guy JS (2018) Niklas Luhmann before relational sociology: the cybernetics roots of systems theory. Syst Res Behav Sci 35(6):856-868. https://doi.org/10.1002/sres.2523

Hafer CL, Rubel AN, Drolet CE (2019) Experimental evidence of subtle victim blame in the absence of explicit blame. PLoS ONE. https://doi.org/10.1371/journal.pone.0227229

Hameleers M, Bos L, de Vreese CH (2017) 'They did it': the effects of emotionalized blame attribution in populist communication. Commun Res 44(6):870-900. https://doi.org/10.1177/0093650216644026

Hanson B (1995) General systems theory beginning with wholes. Taylor \& Francis, Washington

Hanson B (2010) Towards a model of contextual emotional dynamics of illness: senile dementia versus cancer as a case in point. Int Rev Mod Sociol 36(1):53-73

Hanson B (2014) What holism can do for social theory. Routledge studies in social and political thought. Routledge, New York

Hanson B (2016) Blame dynamics and holism in dispute resolution. Mayhew-Hite Report on Dispute Resolution and the Courts. The Ohio State Journal on Dispute Resolution, in collaboration with the Moritz College of Law's Program on Dispute Resolution, vol 15(1). http://www.moritzlaw.osu.edu/ mayhew-hite-report/mhr/10-10-16/

Hansson S (2018) The discursive micro-politics of blame avoidance: unpacking the language of government blame games. Policy Sci 51(4):545-564. https://doi.org/10.1007/s11077-018-9335-3

Harrington J (1561-1612) On Treason. https://books.google.ca/books?id=MEEPAQAAMAAJ\&pg= PP281\&lpg=PP281\&dq=why+doth+treason+never+prosper+university \&source=bl\&ots=-TIITb Tytr\&sig=ACfU3U2GWARyiWqcY6eCDVpIKv9B9_rKyQ\&hl=en\&sa=X\&ved=2ahUKEwjym uHi7LXoAhUaCs0KHdlpDf4Q6AEwEXoECAwQAQ\#v=onepage\&q=why\%20doth\%20treason \% 20never\%20prosper\%20university\&f=false. Accessed 25 Mar 2020

Heinkelmann-Wild T, Kriegmair L, Rittberger B (2020) The EU multi-level system and the Europeanization of domestic blame games. Polit Govern 8(1):85-94. https://doi.org/10.17645/pag.v8i1.2522

Hinterleitner M, Sager F (2017) Anticipatory and reactive forms of blame avoidance: of foxes and lions. Eur Polit Sci Rev (EPSR) 9(4):587-606. https://doi.org/10.1017/S1755773916000126

Jackson MC, Sambo G (2020) Health systems research and critical systems thinking: the case for partnership. Syst Res Behav Sci 37(1):3-22. https://doi.org/10.1002/sres.2638

Joyce K, Jeske M (2019) Revisiting the sick role: performing regimes of patienthood in the 21st century. Sociol Viewpoints 33(1):70-90

Khoury L (2013) Geopolitics of knowledge: constructing an indigenous sociology from the south. Int Rev Mod Sociol 39(1):1-28

Kirk SFL et al (2014) Blame, shame, and lack of support: a multilevel study on obesity management. Qual Health Res 24(6):790-800. https://doi.org/10.1177/1049732314529667

Knio K (2018) The morphogenetic approach and immanent causality: a spinozian perspective. J Theory Soc Behav 48:398-415. https://doi.org/10.1111/jtsb.12181

La Barbera MC, López MC (2019) Toward the implementation of intersectionality in the European multilevel legal praxis: B S. v. Spain. Law Soc Rev 53(4):1-35

Malle BF, Guglielmo S, Monroe AE (2014) A theory of blame. Psychol Inq 25(2):147-186. https://doi. org/10.1080/1047840X.2014.877340

Mant J (2020) Working politically: combining socio-legal tools to study experiences of law. German Law J 21(7):1464-1480

Maruyana M (1963) The second cybernetics: deviation-amplifying mutual causal processes. Am Sci 51:164-179

Mavrofides T, Kameas A, Papageorgiou D, Los A (2011) On the entropy of social systems: a revision of the concepts of entropy and energy in the social context. Syst Res Behav Sci 28:353-368

McDaniel S (2003) The demographic category as leaky gender boundary: implications for women's reproductive health. Womens Health Urban Life 2(1):4-21 
Meers J (2019) Discretion as blame avoidance: passing the buck to local authorities in 'welfare reform.' J Poverty Soc Justice 27(1):41-60. https://doi.org/10.1332/175982718X15451305440442

Nadler J (2012) Blaming as a social process: the influence of character and moral emotion on blame. Law Contemp Probl 75(2):1-31

Phelan G (2013) Stigma, perceived blame, self blame, and depressive symptoms in men with colorectal cancer. Psycho-Oncology (chichester, England) 22(1):65-73

Reiter B (2020) Fuzzy epistemology: decolonizing the social sciences. J Theory Soc Behav 50:103-118. https://doi.org/10.1111/jtsb.12229

Rousseau P (2011) Blame. Palliat Support Care 9(3):335-336. https://doi.org/10.1017/S14789515110002 90

Royakkers L, Hughes J (2020) Blame it on me. J Philos Logic 49:315-349. https://doi.org/10.1007/ s10992-019-09519-7

Smith DE (1987) The everyday world as problematic: a feminist sociology. University of Toronto Press, Toronto

Stalker GJ (2019) What is leisure without becoming? Assemblages of active and reactive leisure. Leisure Sci 41(5):348-365. https://doi.org/10.1080/01490400.2019.1627961

Thörel N, Thörel E, Tuschen-Caffier B (2020) Differential stigmatization in the context of eating disorders: less blame might come at the price of greater social rejection. Stigma Health 6(1):100-112

Tilley C (2008) Credit and blame. Princeton University Press, Princeton

Trudean J (2017) Macleans Magazine Website. https://www.macleans.ca/news/canada/read-justin-trude aus-apology-to-residential-school-survivors-in-newfoundland/

Trudeau J (2020) Intolerance and Racism have no place in this country. April 23. https://www.cbc.ca/ player/play/1728608835587

Unthank KW (2019) How self-blame empowers and disempowers survivors of interpersonal trauma: an intuitive inquiry. Qual Psychol 6(3):359-378. https://doi.org/10.1037/qup0000136

Vanderstraeten R (2019) Systems everywhere? Syst Res Behav Sci 36(3):255-262. https://doi.org/10. $1002 /$ sres.2596

Wallis SE (2014) A systems approach to understanding theory: finding the core, identifying opportunities for improvement, and integrating fragmented fields. Syst Res Behav Sci 31(1):23-31. https://doi. org/10.1002/sres.2159

Wallis SE (2020) Orthogonality: developing a structural/perspectival approach for improving theoretical models. Syst Res Behav Sci 37(2):345-359. https://doi.org/10.1002/sres.2634

Watzlawick P, Bavelas JB, Jackson DD (1967) Pragmatics of human communication. W.W. Norton \& Company, New York

Williams E (2020) Attributing blame? - climate accountability and the uneven landscape of impacts, emissions, and finances. Clim Change 161:273-290. https://doi.org/10.1007/s10584-019-02620-5

Zebellos-Reig J (2020) Mike Bloomberg once blamed banks making loans to black Americans as the cause for the 2008 financial crash. https://markets.businessinsider.com. Accessed 21 Sept 2020 